\title{
High Resolution Sequence Stratigraphy Correlation and Sedimentary Model of Braided Rivers: A Case on Paleogene Palogue Oilfield, South Sudan
}

\author{
Zhao Ning $^{* 1}$, Gao Xia ${ }^{1}$, Chen Zhongmin ${ }^{1}$, Huang Jiangqin ${ }^{2}$ and Zhang Guangya ${ }^{1}$ \\ ${ }^{1}$ PetroChina Research Institute of Petroleum Exploration and Development, 100083 Beijing, China \\ ${ }^{2}$ CECEP L\&T Environmental Technology, 100085 Beijing, China
}

\begin{abstract}
Complicated fluvial sands correlation and braided river models are still challenges for heterogeneous anisotropic reservoir evaluation for petroleum development in oilfields. Based on high-resolution sequence stratigraphy and sedimentology, core observation, and the analysis of logging and seismic data, high-resolution sequence stratigraphy framework of Paleogene Yabus formation of Palogue Oilfield, South Sudan is established, and sedimentary characteristics of braided rivers are analyzed, (1) In braided river deposits, channel bars are usually pro-gradating seawards and going thicker upwards. And braided channels are retro-gradating landwards and going thinner upwards. Both of them can be subdivided into channel (bar) trunks and channels (bar) flanks, showing vertical stacking and lateral migration; (3) As the A/S (Accommodation space/sediments supply) increasing upwards, braided river sands are shifting frequently as a reciprocating migration in Yabus V/VI, and they are more stable as the A/S decreasing upwards as a vertical aggradation in Yabus VII/VIII; (4) With 77 wells sedimentary microfacies identification, sand thickness and sand/bed ratio distribution, sedimentary facies distribution of all members and zones are analyzed. According to the A/S change, three braided river models are concluded, including isolated channel type (high A/S period), crossed channels type (medium A/S period), and superposed channels type (low A/S period).
\end{abstract}

\section{Introduction}

Several braided river models have been concluded according to bed geometry, flow and sedimentary process [1], or sediment type, sinuosity, braiding parameter and characteristic elements [2]. They all considered about flow mechanism, characteristics of braided river deposits, and summed up braided river models according to grain size, sinuosity, bed geometry, and sedimentary micro-facies units. However, they didn't establish the relationship between flow mechanism and characteristics of braided river deposits. Taking braided river deposits in Yabus formation in Pal block of Palogue oilfield, South Sudan 3/7 Area as an example, this text applied outcrops and cores observation, well logs and seismic inversion data of braided river deposits, doing analysis of sedimentary characteristics and depositional evolution, and concluded sedimentary models according to accommodation space and sediments supply (A/S) view of high-resolution sequence stratigraphy. These models can illustrate the relationship between braided river characteristics and $\mathrm{A} / \mathrm{S}$ change.

In the theory of sequence stratigraphy originated from passive continental margin on seismic data, sequence stratigraphy can be identified by different levels of truncations or unconformity, such as onlaps, downlaps, toplaps. on seismic reflection configuration (Fig.1A). However, in a fluvial or a deep lake or marine deposits, where lack of these regional seismic reflections, it is difficult to figure out sequence boundary, even sequence stratigraphy correlation. Therefore, doing strata correlation according to lithology surface (sands - shales mutation) or physical surface (overlaps or unconformity) is not adapt to sequence stratigraphy division and correlation of braided river deposit for their quick-change river channels (Fig.1B). when doing with thick overlaid sands correlation, as shown in Fig.1C (Paul Weimer, 2009), how can we deal with it. These are problems when doing braided river study.

\footnotetext{
* Corresponding author: E-mail: williams8021@petrochina.com.cn. ZHAO Ning, Tel: +86 108359 3191, Fax: +86 1083598042. Address: No.20, Xueyuan road, Haidian district, Beijing, China.
} 


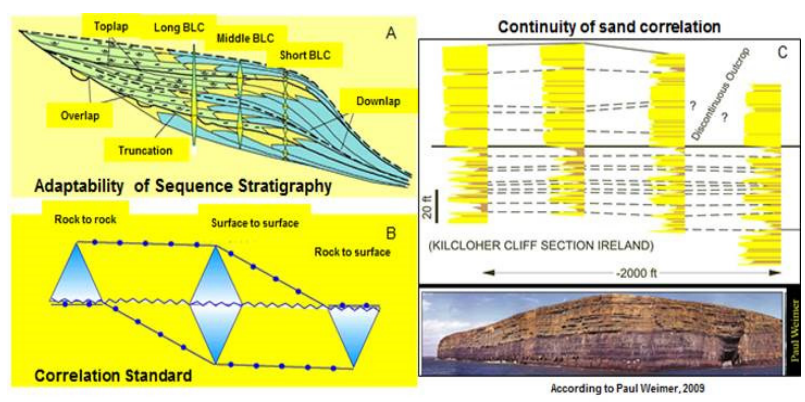

Fig.1 Questions in sequence stratigraphy of fluvial deposits (A. Adaptability of sequence stratigraphy theory; B. Correlation standard: lithology surface or physical surface; C. Continuity of overlaid sand correlation and geological outcrop according to Paul Weimer, 2009)

\section{Geological Settings}

Melut basin locates on northeast South Sudan (Fig.2A), and southern part of east central Africa shear zones, with a narrow northwestern and wide southeastern wedge shape (Fig.2B) and $33.2 * 103 \mathrm{~km}^{2}$. It has five half-graben depressions, i.e., northern, eastern, center, southern and western depression, echelon arranging in NW-SE direction, and one western uplift, and northern depression is the largest, with $3500 \mathrm{~km}^{2}$ area. Melut is a Mesozoic-Cenozoic intracontinental rift basin, induced by central Africa shear zones slant rifting [3-4]. Palogue oilfield locates on northwest Melut basin (Fig.2B). It is an anticline structural belt, raised by basement uplifting, with nearly $530 \mathrm{~km}^{2}$, separated by northwest to southeast direction faults, and can be divided into 10 blocks (Fig.2C), and Pal block is one of most oil productive areas, more than five million barrels totally.

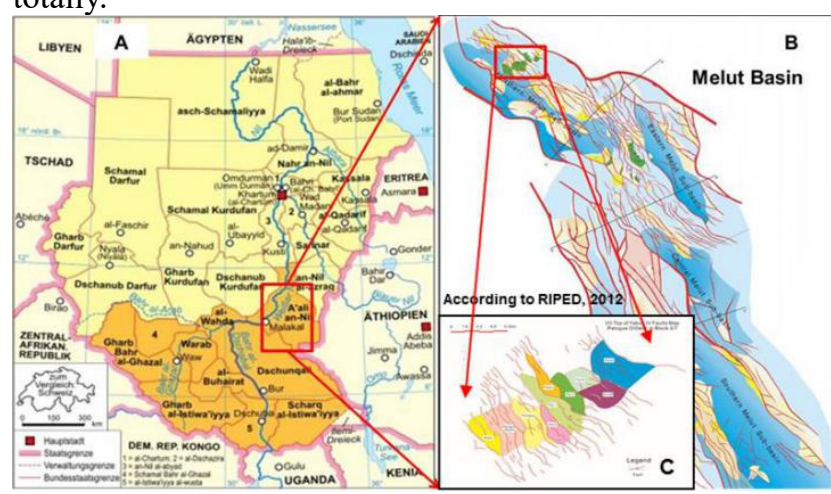

Fig.2 Location and structural background of Palogue oilfield. Melut basin, South Sudan (A. location of Melut basin, northeast South Sudan; B. Structural background of Melut basin, the lighter color, the structural higher, and Palogue oilfield on northwestern uplifts in Melut basin; C. 10 blocks of Palogue oilfield, and Pal block is one of anticlines in the oilfield, divided by large faults)

\section{High resolution sequence stratigraphy}

Considering about seismic sequence stratigraphy division cannot give the fine results about frequently changing braided river deposits for its low precision, high resolution sequence stratigraphy (HRSS) theory is used. Based on this theory, (1) base level is a potentiometric surface, not a definite one, and (2) in high Accommodation / Sedimentary supply (A/S), sedimentary facies preservation is good, vertical gradation is clear, and sands are isolated distributed vertically; In low $\mathrm{A} / \mathrm{S}$, sedimentary facies preservation is bad, vertical gradation is unclear, and sands are superposed vertically; (3) Depositional volume is different according to various depositional environment; (4) According to the variation of accommodation and sediment supply, base level shows a dynamic balance, deposition or erosion (starvation), and rising and falling periods can be divided in one cycle. Therefore, this theory creates a new correlation standard, not restricted to definite unconformity surfaces. Therefore, it is adaptable to multi-periods deposits, especially overlaid sands correlation.

From Cretaceous to Neogene, the oilfield structure changes from rifting into depressing period (the $1^{\text {st }}$ grade sequence), and between these two periods, regional unconformity was spreading the whole oilfield (Fig.3). From Paleocene to Oligocene epoch, one intact base level cycle (BLC, the $2^{\text {nd }}$ grade sequence) was included, and maximum flooding surface is in Adar formation with medium amplitude, low frequency and week continuity in seismic (Fig.3). Yabus (Y) and Samaa formation each have one intact BLC (the $3^{\text {rd }}$ grade sequence), including rising and falling period. Comparing the two formations, Samaa formation is more sandy, with week amplitude, low frequency and week continuity in seismic. However, Yabus formation is more shaly, and YI-YIII sub-formations upwards are more shaly, with high amplitude, medium frequency and low continuity in seismic, than YIV-YVIII sub-formations downwards, with high amplitude, high frequency and high continuity in seismic reflection (Fig.3). Therefore, high resolution sequence stratigraphy division schedule of Palogue oilfield has been constructed.

The progress of HRSS correlation, which is the key step for braided river sands distribution study, concludes four steps [5-9]. (1) Choosing a stable, large distribution, and easy tracing marker, and usually choose thick shales in a stable depositional environment as a regional marker. According to well logs, $20-30 \mathrm{~m}$ thick shales in Adar formation can be the regional marker in this area. The thickness of marker is relatively stable, and easy tracing in seismic sections; (2) Combining geological and geographical methods, such as seismic data consulting, well logs correlation and core observation, and matching the results of such methods. Considering the process of braided river formation, from the hydraulic power change view, sequence stratigraphy division on cores has been done, according to colors, beddings and sand/shale type of cores (Fig.4). Further, analysis about well logs and seismic data gives more information about regional sequence stratigraphy, and also hydraulic power change; (3) Identifying multi-grade rising and falling BLC periods, and transitional surfaces, including sequence boundary or maximum flooding surfaces. Sequence stratigraphy division should follow the progress, from the 
lower grade (unconformities in seismic and well logs for the whole area) to the higher grade (hydraulic changes in cores observation). Core color (black, brown, green, red or white) give some information about the environment, such as oxidation - deoxidation condition, rock components or strata characteristics; beddings (horizontal bedding, wave bedding, oblique bedding, trough cross bedding, and so on) show hydrodynamic condition, i.e., laminar / turbulent flow, relatively strong or weak; and sand/shale type (shale, slits or sand layer) indicates loading capacity when deposition happens. As shown in Fig.4, hydraulic power variates with BLC change. Cores color, beddings and sand/shale type give the result of hydraulic power variation, changing from channel bars in primary falling BLC cycle to braided channels in primary rising BLC cycle. With well logs, sedimentary facies identification Jumping particles are priority in shallow layers and suspending particles are priority in lower layers shown in grain size probability cumulative curves (Fig.4).

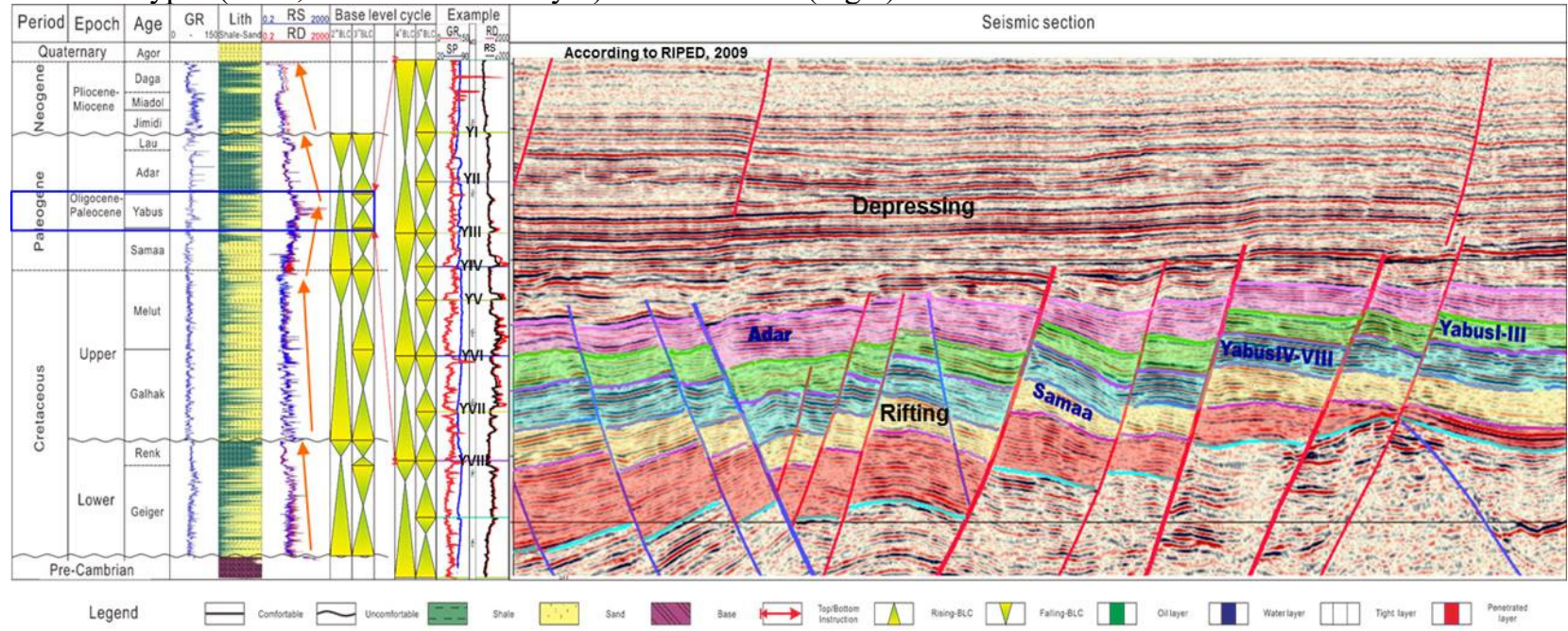

Fig.3 High resolution sequence stratigraphy framework and structure background from Cretaceous to Neogene (the left figure shows high resolution sequence stratigraphy framework in the whole Palogue oilfield, from Paleogene to Neogene period, it shows rising stage the 1st grade BLC, and Paleogene period concludes one intact 2nd grade BLC and three the 3rd grade BLCs. Moreover, Yabus formation can be divided into three the 4th grade BLCs and eight the 5th grade BLCs, according to well logs variation; the right figure shows tectonic change from rifting to depressing and seismic characteristics changing from Paleogene to Neogene period. Adar formation is more shaly, and Samaa formation is more sandy, compared with Yabus formation. Moreover, YI-YIII sub-formation is more shaly compared by YIV-YVIII sub-formation.)
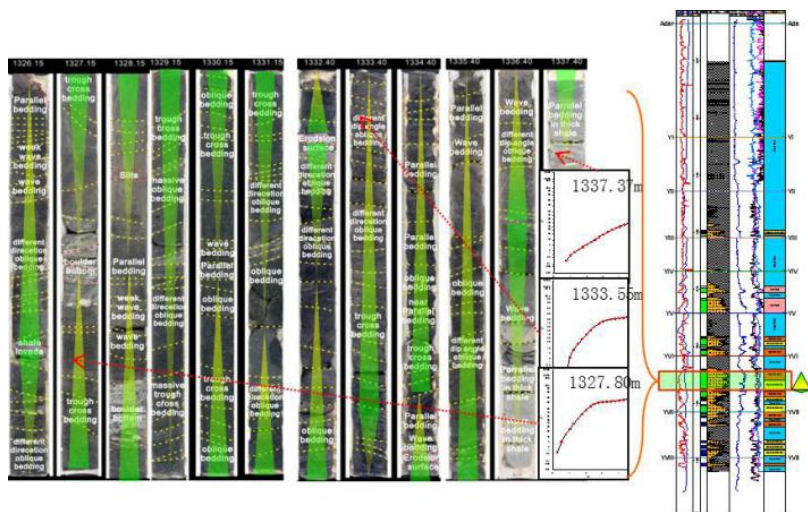

Fig.4 High resolution sequence stratigraphy division in core observation, well logs and grain size probability cumulative curves

When doing the sequence stratigraphy correlation, sediments distribution both in lateral and planar should be considered. Compared with well sections both vertical and parallel to provenance supply direction, strata trend and bed thickness are different. Strata is always uneven, fluctuated, and bed thickness is frequently changed with 25-50m thickness vertical to provenance supply direction; however, strata is stable with anticline shape across the section, and bed thickness has little difference with 30-35m thickness parallel to provenance supply direction.
Therefore, high resolution sequence stratigraphy framework has been built. 


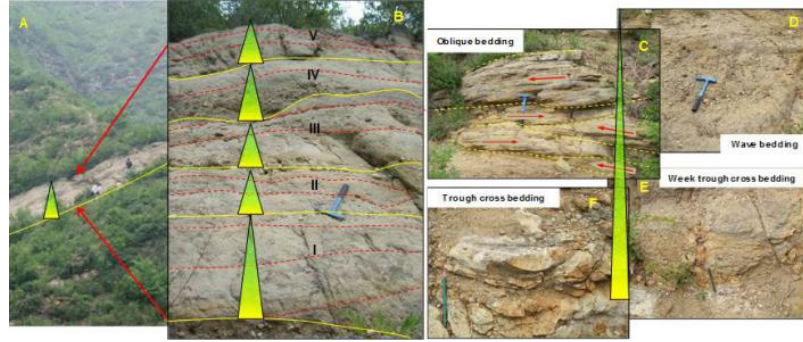

Fig.5 Braided river outcrop in petrified wood national geological park in Beijing, China (A. Braided river channel sands overlaid vertically, B period I, II, III, IV and V; from C to $\mathrm{F}$, hydraulic power is increasing downwards, and channel bars show both vertical stacking and lateral migration.)

\section{Sedimentary characteristics models}

\subsection{Outcrops of braided river deposits}

Braided river outcrops observation can give some information about sedimentary face types, hydrodynamic condition, paleotopography in depositional period, sands vertical superposed stacking patterns and lateral distribution law. In braided river deposits, many scholars may think vertical superposition is the main stacking pattern of braided channel or channel bar sands (Fig.5A, Fig.5B, Fig.7B), as shown in Fig.7, three sand layers constitute the rising stage BLC, with $25-35 \mathrm{~cm}$ sand thickness vertically, and $20-25 \mathrm{~cm}$ sand thickness laterally. As in petrified wood national geological park braided river channels deposits, one rising stage BLC of the $3^{\text {rd }}$ grade sequence can be subdivided into five rising stages BLC of the $4^{\text {th }}$ grade sequence. Moreover, three stages of sands overlaid vertically in each period, and sands thickness grows thinner upwards (Fig.5B) (1) However, braided river sands always show vertical superposing and lateral migrating in nature, for the frequent water flow changing. As in petrified wood national geological park channel bar deposits, sand layers are showing a reciprocating stacking pattern, indicating frequently changing back and forth water flow mechanism, hydraulic power is increasing downwards, from wave bedding, oblique bedding, week trough cross bedding to trough cross bedding, showing the rising stage BLC vertically. Moreover, channel bars show both vertical stacking and lateral migration (Fig.5C-Fig.5F). (2) Moreover, braided channels and channel bars always interact with each other, showing lateral stacking patterns (Fig.6, Fig.7A), as main braided channels contacting with channel bar flanks or main channel bars joint with braided channel flanks, and sometimes braided channel sands act as a progradation or retrogradation pattern, showing water flow direction in deposition. As shown in Fig.6, braided channels and channel bars are vertical stacking and lateral migrating with each other. Braided channel sands are multi-period overlaid vertically, with gravels directional arrangement at the bottom and parallel beddings in the center. Three stages of sands are overlaid vertically, with grain size grows smaller upwards, forming the rising stage BLC of the $5^{\text {th }}$ grade sequence, and the thickness of sands turns smaller upwards, still composing the rising stage BLC with the $4^{\text {th }}$ grade sequence in Fig.7B. Sometimes, shales in braided river depositional system may be considered near the flooding surface for their fine grain size, and normally locate on the transformation from the rising to falling stage BLC. (3) However, calcareous nodules in red shales are growing less and smaller upwards in the rising stage BLC, and shrinkage cracks or vertisols are well developed in falling stage BLC, indicating an exposed or uncovered depositional environment, and paleosol layers with calcareous nodules locate in the center, which show a very drought condition from falling to rising stage BLC transformation for its low accumulation space. Four BLCs of braided river deposits, from paleosol layers with calcareous nodules to red shales (Fig.7D) and then to thick gravels upwards forming one intact BLC. Moreover, from thick gravels to red shales and then to paleosol layers upwards constituting another intact BLC, and then repeating the depositional progress again (Fig.7C). Therefore, hydrodynamic mechanism of braided river sands formation, superposition and correlation are figured out through

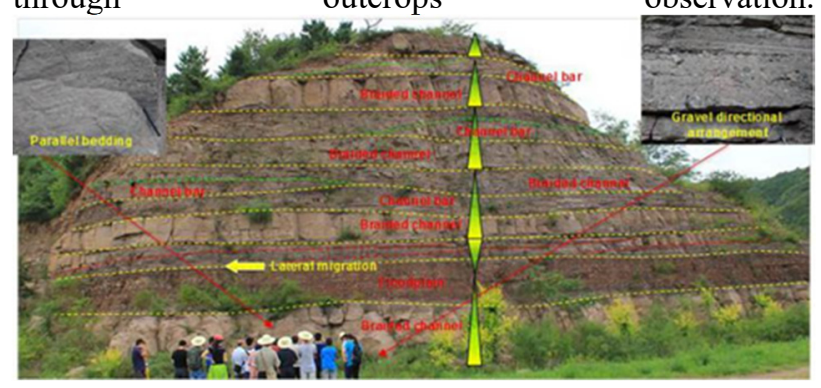

Fig.6 Braided river outcrop of lower Cretaceous in Hebei, China (Five periods braided river sands deposits, including braided river channels and channel bars.)
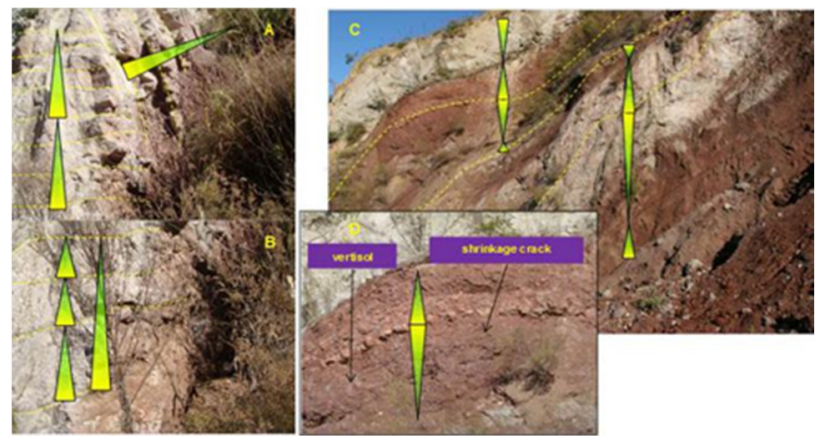

Fig.7 Braided river outcrop in the $4^{\text {th }}$ member of Quantou formation in Jilin, China (A. Braided river channel sands overlaid vertically and migrated laterally; B. Three stages of sands are overlaid vertically; C. Four BLCs of braided river deposits, from paleosol layers with calcareous nodules to red shales (D) and then to thick gravels upwards forming one intact BLC.)

\subsection{Sedimentary facies classification and distribution}

According to core data, outcrops and well logs, two sedimentary sub-facies and five microfacies of braided 
river deposits are identified (Table.1), including channel sub-facies (i.e., braided channel, channel bar, channel suspension) and inter-channel sub-facies (i.e., overbank, flooding plain), and braided channel and channel bar are most important sands in braided river reservoirs. Braided channels are grey or green color, from conglomeratic coarse sandstones to fine sandstones upwards (fining upwards), with thin monolayer (the thickness is no more than $10 \mathrm{~m}$ ) and overlaid multilayers vertically. Trough cross beddings, oblique beddings or parallel beddings with erosion surface at the bottom are well developed, indicating high hydraulic power and quickly stacking depositional condition. Therefore, shales can hardly deposit, showing "bell or box" shape in GR (fining upwards). For its multi-periods and interval flooding flow, braided channels are retrograding landwards and frequently changing in lateral distribution (Fig.6). Moreover, according to different accumulation space, channel trunks are formed in high $\mathrm{A} / \mathrm{S}$ period, with narrow-deep river bed, low provenance supply, fine grain size, intraclast bounder clay at the bottom and lots of fine-grain overflows; channel flanks are formed in low $\mathrm{A} / \mathrm{S}$ period, with wide-shallow river bed, high provenance supply, coarse grain size, interclast bounder clay at the bottom and little overflow deposits (Table.1).
Channel bars are coarse grain sands blocking fine grain sands in river center or flank for hydraulic power change, caused by braided channels frequent change and topography modification. They are grey, green or white color, from medium sandstones to coarse sandstones upwards (coarsing upwards), with thick monolayer (the thickness is $8-30 \mathrm{~m}$ ) and thick overlaid multilayers vertically. Oblique beddings, trough cross beddings with erosion surface at the bottom and shale interlayers between sand layers are well developed, indicating high hydraulic power and frequent change water flows. Therefore, they usually show "jugged box or funnel" shape in GR (coarsing upwards), with prograding seawards and different direction axis of elliptical shape in lateral distribution (Fig.6). Like braided channels, channel bars can also be divided into bar trunks and bar flanks. However, according to different accumulation space, bar trunks are formed in low A/S period, with wide-shallow transverse bars, high provenance supply, coarse grain size, and lateral migration on the priority; bar flanks are formed in high $\mathrm{A} / \mathrm{S}$ period, with narrow-deep longitudinal bars, low provenance supply, fine grain size, and vertical staking on the priority (Table.1).

Table.1 Sedimentary facies division of braided river (Braided channels and channel bars can be divided into channel (bar) trunks and channel (bar) flanks according to their relative location)

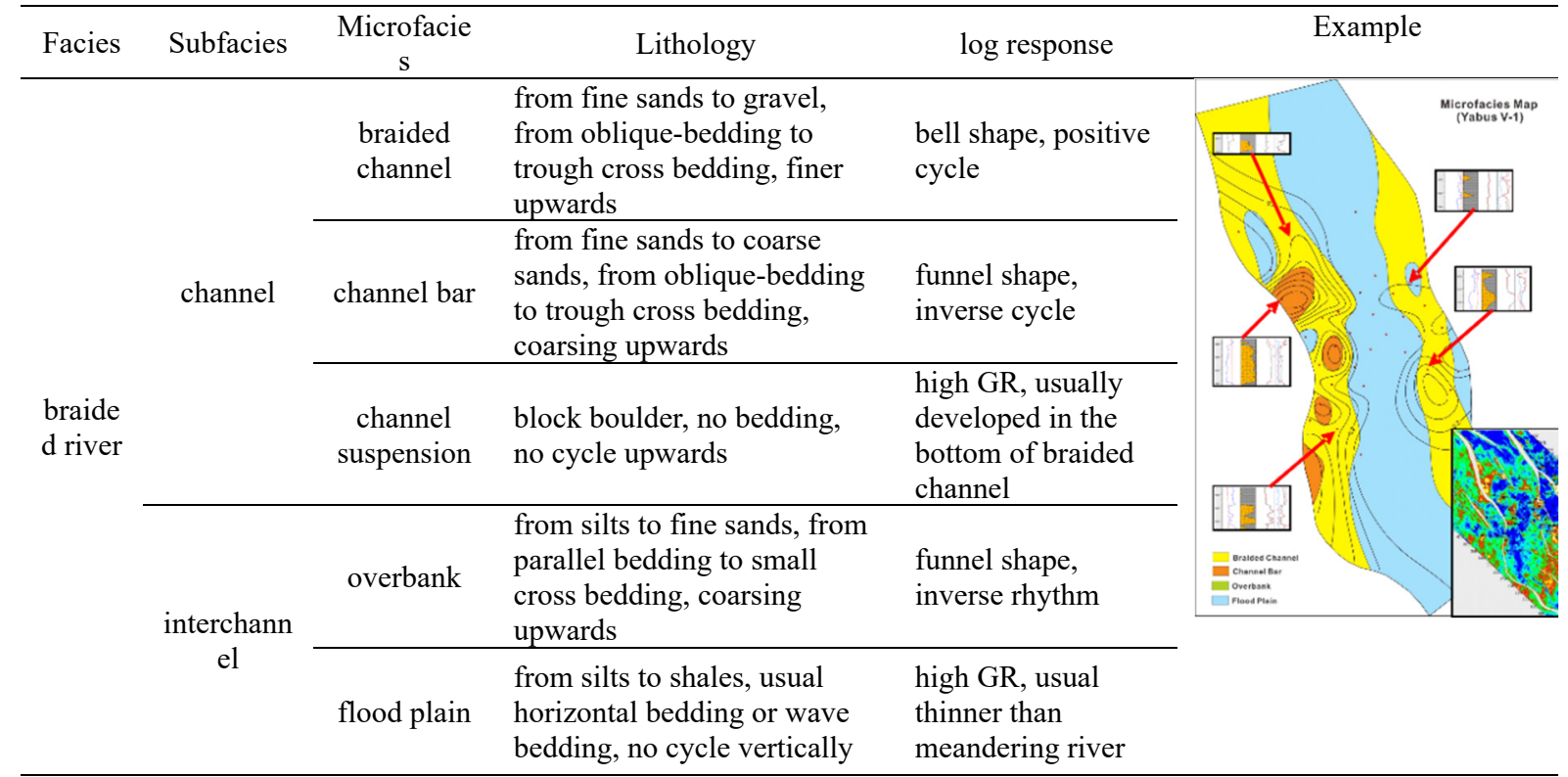

Comparing sedimentary micro-facies of braided river sands with parallel to or vertical to provenance supply direction, sands distributions are different. When parallel to provenance supply direction, braided channels are relatively stable, and channel bars are vertical superposing more than lateral migrating, with good sands continuity, for high accumulation space and low provenance supply (Fig.8A); however, when vertical to provenance supply direction, braided channels are frequently changed, channel bars are lateral migrating more than vertical superposing, with bad sands continuity, for low accumulation space and high provenance supply (Fig.8B). 


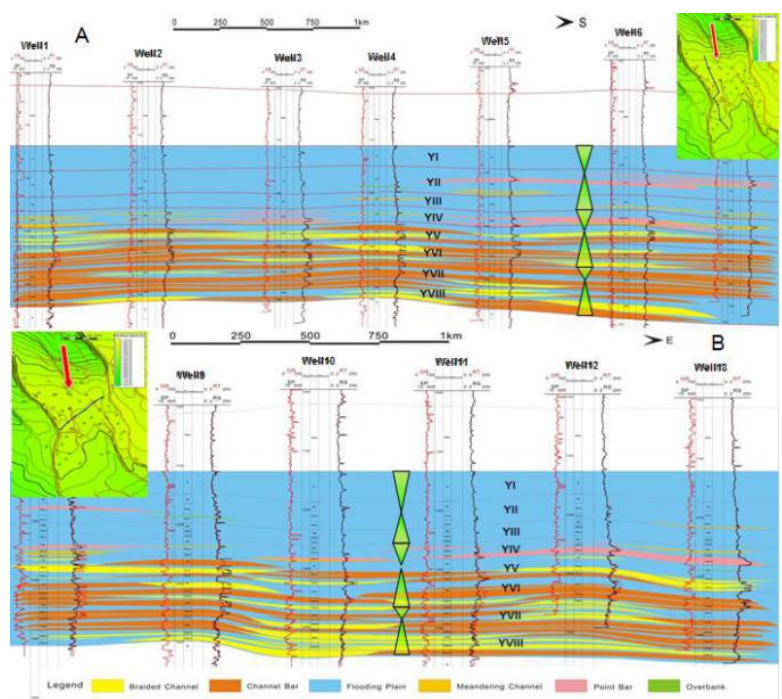

Fig.8 Sedimentary micro-facies of braided river sands correlation with different direction (A. Braided river sands correlation parallel to provenance supply; B. Braided river sands correlation vertical to provenance supply.)

According to 77 wells microfacies identification, sand thickness and sand/bed ratio calculation, braided rive sands distribution in every zone and every sand layer have been done. From the top to the bottom, braided channels are changing from narrow distributed, single channel to wide distributed, crossed channel, and the long axis of channel bars vary from NW-SE (parallel to provenance supply) to SW-NE (vertical to provenance supply), with larger and larger distribution. As shown in Fig.9, braided channels and channel bars are changing from narrow, single channel to crossed channel, and channel bars are larger and larger from zone YV1 to zone YV3 with A/S decreasing downwards. Moreover, compared with every sub-zone of Yabus formation (Fig.10), braided channels and channel bars show the same changes as every zone in Fig.9, and also more sands distribution downwards in every sub-zone with $\mathrm{A} / \mathrm{S}$ decreasing.

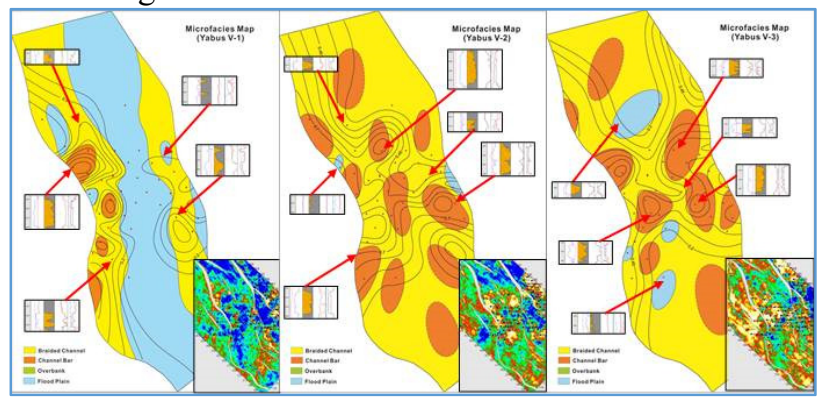

Fig.9 Sedimentary microfacies distribution of braided river sands with seismic inversion results (according to microfacies identification, sand thickness and sand/bed ratio calculation, braided rive sands distribution from zone YV-1 to zone YV-3)

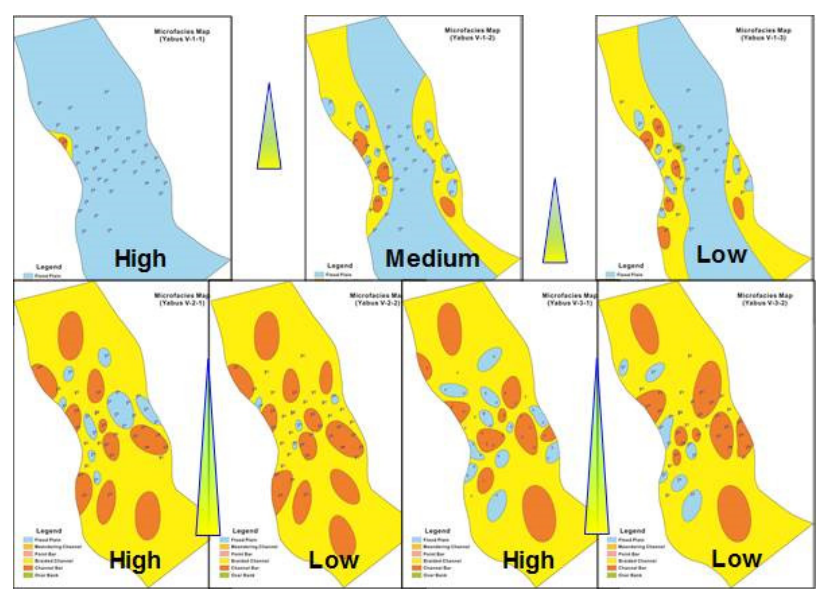

Fig.10 Sedimentary micro-facies distribution of braided river sands in every zone (from upper YV-1-1 3 to lower YV-2-1 2 or YV-3-1 2 zones, braided river sands shows the rising period of $\mathrm{BLC}$ change, that is from high $\mathrm{A} / \mathrm{S}$ to low $\mathrm{A} / \mathrm{S}$ change.)

\subsection{Sedimentary facies models of braided river deposits}

According to water level, bed structural and grain size, nine kinds of braided river model were concluded by A.D. Miall (1996), i.e., gravel-bed braided river with sediment gravity flow, shallow gravel-bed braided river, deep gravel-bed braided river, low sinuosity river with alternate bras, shallow perennial sand-bed braided river, deep perennial sand-bed braided river, high energy sand-bed braided river, distal sheet flood sand-bed river, flashy ephemeral sheet flood sand-bed river [2]. According to braided river formation and $\mathrm{A} / \mathrm{S}$ change, three types of braided river sedimentary model are concluded. In the high $\mathrm{A} / \mathrm{S}$ period, braided channels are separated with each other, overbanks are developed between channels, and most of channel bars are small and arbitrary assembling. Therefore, it is can also be called isolated channel type, and characterized by poor sands and rich shales (Fig.11A). This isolated channel type of braided river is in high accommodation space and low sediments supply condition, and transits to meandering river with hydrodynamic power decreasing in a lower elevation. However, in low $\mathrm{A} / \mathrm{S}$ period, braided channels are superposed with each other; and most of channel bars are large compared to isolated channel type, and always along with currents direction. So it can also be called superposed channel type, and characterized by rich sands and poor shales (Fig.11C). This superposed channel type of braided river is in low accommodation space and high sediments supply condition. In medium $\mathrm{A} / \mathrm{S}$ period, braided channels are intersected with each other; and most of channel bars are also arbitrary assembling, and it is called crossed channel type, and characterized by medium sand shale ratio (Fig.11B). This crossed channel type of braided river is in relatively lower accommodation space and higher sediments supply condition with the former one, and transits into superposed channel type with more sand content. For example, Congo river goes from northeast to southwest and into Atlantic Ocean, and in lower stream 
of Congo river, it shows one braided river going from southwest to northeast direction, and the $1^{\text {st }}$ grade isolated braided channel separated into two secondary grade braided channels with relatively small hydrodynamic power, and over banks are developed in the concave bank side (Fig.11A). In the middle part of Congo river, river flows from north to south direction, lots of channel bars and crossed channels in the river, and no over banks are developed (Fig.11B). In the higher stream of Congo river, river also flows from north to south direction, lots of channel bars with water flow direction and superposed channels in the river (Fig.11C).
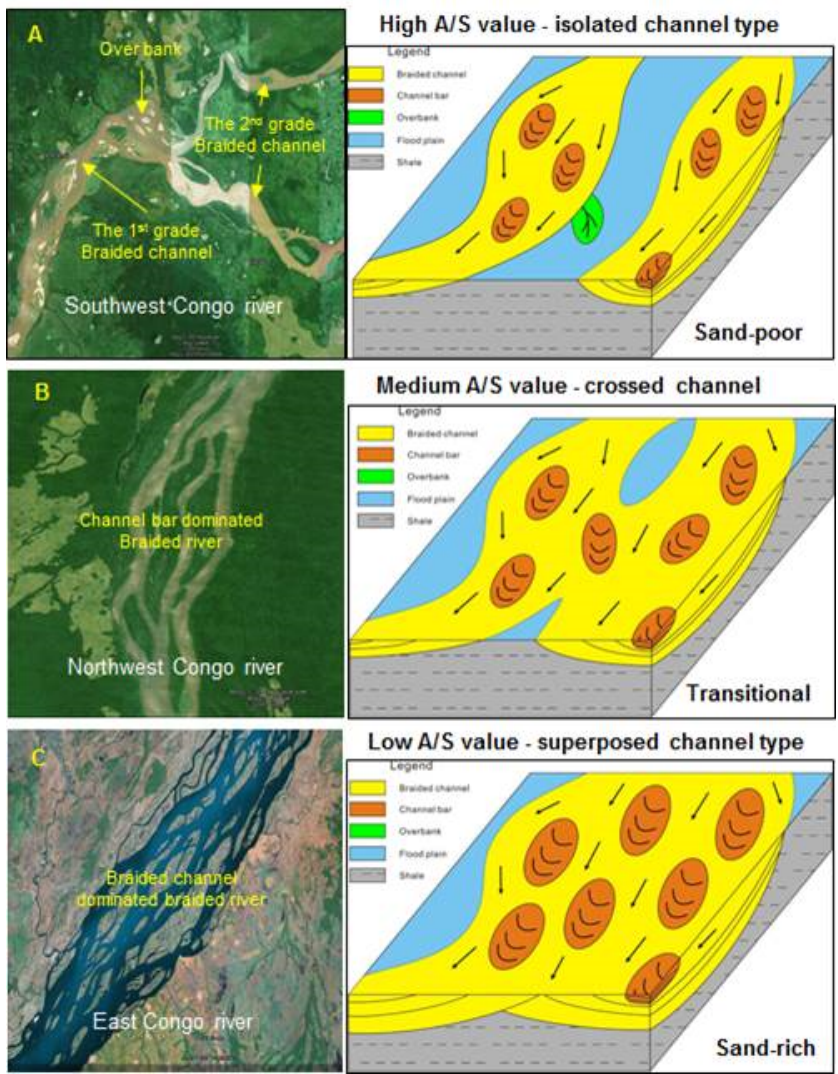

Fig.11 Three types of braided river according to A/S change (A. isolated channel type, poor in sands and rich in shales; B. crossed channel type, medium sand/shale ratio; C. superposed channel type, rich in sands and poor in shales)

\section{Conclusions}

From the above considerations of sequence stratigraphy correlation and sedimentary facies analysis of braided river in Palogue oilfield of South Sudan, Accommodation and sediments supply change can be effective in explaining the sedimentation process of braided river, including sands lateral migration and vertical staking pattern, especial superposed sands correlation. Therefore, according to $\mathrm{A} / \mathrm{S}$ change, three sedimentary models of braided river have been built up, including isolated channel type (in high $\mathrm{A} / \mathrm{S}$ period), crossed channel type (in medium $\mathrm{A} / \mathrm{S}$ period), and superposed channel type (in low $\mathrm{A} / \mathrm{S}$ period).

\section{Acknowledgment}

Supported by National Science and Technology key Project No.29: Target evaluation of overseas key exploration areas and research on selection zones and areas in future (2016ZX05029005)

\section{REFERENCES CITED}

1. John S. Bridge and Ian A. Lunt. Depositional models of braided rivers. In: Braided rivers: process, deposits, ecology and management (Eds G. H. Sambrook Smith, J. L. Best, C. S. Bristow and G. E. Petts). Special publication No.36 of the international association of sedimentologists. Blackwell publishing, Oxford, 11-42 (2006)

2. Miall A.D. Fluvial style and facies models. In: The geology of fluvial deposits: sedimentary facies, basin analysis, and petroleum geology (Eds A. D. Miall), Springer, Italy, 191-250 (1996)

3. Genik J.G. Petroleum Geology of Cretaceous-Tertiary Rift Basins in Niger, Chad, and Central African Republic, AAPG, 77, 1405 -1434 (1992)

4. Genik J.G. Regional framework, structural and petroleum aspects of rift basins in Niger, Chad and the Central African Republic, Tectonophysics, 213, 169-185 (1993)

5. Cross $\mathrm{T}$ A. Controls on coal distribution in transgressive-regressive cycles, upper Cretaceous, Western Interior, U.S.A., in Wilgus, C.K., et al., Sea-level changes: An intergrated approach, Society of Economic Paleontologists and Mineralogists Special Publication 15, 293-308 (1988)

6. Cross T.A., Maker M.R., et al,. Applications of High-resolution Sequence Stratigraphy to Reservoir Analysis. In: Proceedings of the $7^{\text {th }}$ Exploration and Production Research Conference, Paris. 11-13 (1993)

7. Cross T A. High-resolutions stratigraphic correlation from the perspective of base-level cycles and sediment accommodations: Proceedings of Northwestern European Sequence Stratigraphy Congress, 105-123 (1994)

8. Cross T A, Lessenger M A. Sediment Volume Partitioning: rational for Stratigraphic Model Evaluation and High-Resolution Stratigraphic Correlation. Norwegian Petroleums, 1-24 (1996)

9. Cross T A, Lessenger M A. Sediment volume partitioning: rationale for stratigraphic model evaluation and high-resolution stratigraphic correlation. Gradstein F M, Sandvik K O, Milton N J, eds. Sequence Stratigraphy Concepts and Applications. NPE Special Publication, 171-195 (1998) 